\title{
RFE based chondroplasty in wrist arthroscopy indicates high risk for chrondocytes especially for the bipolar application
}

\author{
Michaela Huber $^{1 *}$, Christoph Eder ${ }^{1}$, Markus Loibl $^{1}$, Arne Berner ${ }^{1}$, Johannes Zellner ${ }^{1}$, Richard Kujat ${ }^{2}$, \\ Michael Nerlich ${ }^{1}$ and Sebastian Gehmert ${ }^{3}$
}

\begin{abstract}
Background: The application of radiofrequency energy (RFE) has become widespread for surgical performed chondroplasty especially due to the anticipated sealing effect, however the safety of this procedure in the wrist remains unclear. The purpose of this study was to investigate the subchondral temperature during radiofrequency energy (RFE) application simulating chondroplasty in an arthroscopic setting of the wrist.

Methods: A chondroplasty of the lunate fossa was performed during an arthroscopy setting on 14 cadaver arms using monopolar or biopolar RFE. The temperature was recorded simultaneously from 7 predefined anatomical landmarks.

Results: The mean temperature for both application modes did not exceed more than $30^{\circ} \mathrm{C}$ at all measured points, except for the lunate fossa. The highest subchondral measured peak temperature was $49.35^{\circ} \mathrm{C}$ (monopolar) and $69.21^{\circ} \mathrm{C}$ (bipolar) in the lunate fossa. In addition, the temperature decreased for both radiofrequency (RF) devices depending on the distance of the sensors to the RF-probe.

Conclusion: It remains to be questionable how safe RFE can be used for chondroplasty in wrist arthroscopy under continuous irrigation and constant movement to obtain the desired sealing effect. However, the bipolar device should be applied with more caution since peak temperature in the lunate fossa almost reached $70^{\circ} \mathrm{C}$ even under continuous irrigation.
\end{abstract}

Keywords: Temperature, Subchondral, Chondroplasty, RFE, Wrist, Arthroscopy

\section{Background}

Articular cartilage damage progress without treatment in size and grade due to increased permeability which eventually leads to fibrillation, delamination, and swelling [1]. In addition, cartilage affected by degeneration show reduced capacity to absorb compressive load and subsequently provoke crepitus and pain owing to the destructed cartilage surface [2]. Over the last decade radiofrequency energy (RFE) has been applied for chondroplasty of partial-thickness chondral defects in large joints with promising results [3]. Chrondoplasty is used with the intent to terminate or at least to decelerate the degradation of the fibrillated articular cartilage by

\footnotetext{
* Correspondence: michaela1.huber@ukr.de

1Department of Trauma Surgery, University Medical Center Regensburg,

Franz-Josef-Strauss-Allee 11, 93053 Regensburg, Germany

Full list of author information is available at the end of the article
}

smoothing the roughened cartilage surface without the degradation of surrounding intact cartilage. Noteworthy, patient's symptoms have been reported to improve by limiting the degradation of articular cartilage [3,4]. The effect of cartilage smoothing has been termed as "sealing effect" and consistently reported in various studies in which chondroplasty showed an improved morphologic and histological stabilization of damaged cartilage by RFE [5-7].

Turner et al. demonstrated in a sheep animal model for the first time, that bipolar radiofrequency energy (bRFE) might be superior to conventional mechanical shaving (MS) for the treatment of chondromalacic cartilage based on histological criteria. However, viability of chondrocytes have not been analyzed in this study [8]. Recently, Edwards et al. demonstrated in an equine patella model that RFE for cartilage surface smoothing is superior 
to mechanical debridement (MD) due to fewer chondrocyte destruction while maintaining thicker cartilage [9]. However, various studies have been reported that chondrocyte cell death starts at temperatures between $45^{\circ} \mathrm{C}$ to $55^{\circ} \mathrm{C}[10,11]$. Owens et al. reported in a prospective randomized trial that treatment with bRFE was superior to $\mathrm{MD}$ at 12 and 24 month postoperatively [12]. In contrast, Barber et al. did not detect any difference between the groups treated with MD or MD + mRFE (monopolar RFE) after 12 month. However, both studies differ by the applied RFE mode limiting the conclusion that the bipolar RFE might be the best applied modality [3].

Nevertheless, RFE for chondroplasty has been proved to induce less permeability of the cartilage which might lead to a long-term stability [13,14]. Moreover, the inflammatory process in the affected joint appeared to be reduced associated with the decrease of inflammatory mediators $[7,15]$. However, to date only a limited number of clinical trials exist that investigated the effect of RFE for chondroplasty in knee surgery. The empirical evidence regarding the safety and long-lasting effect of RFE is still conflicting hence caution is advised when performing such procedure on cartilage [16].

We decided to mimic a chondroplasty in our previously established hand cadaver model since RFE is frequently performed in the wrist by hand surgeons $[17,18]$. In addition, most of the current research data of RFE originated from studies of large joints. Furthermore, anatomical structures in the wrist are closely spaced and cartilage layer is much thinner when compared to the joints of hip or knee [19]. Thus, experimental data obtained from studies with large joints (i.e. knee, hip) cannot serve as a reliable reference in terms of risk assessment for RFE procedure in wrist.

Based on current literature we hypothesized, that time depended temperature peak might exceed a level leading to injury of chondrocytes and even bone. Furthermore, we expected a difference between bRFE and mRFE application, due to the different energy distribution of the systems.

\section{Methods}

Fourteen upper limbs were obtained from seven fresh cadavers, The cadavers were provided from our Anatomical Institute of the University of Regensburg. Due to the regulations from our ethical board no further requirement exept the written consent of their body cessation for research of the deceased humans prior to death were necessary. The upper limbs were obtained from seven fresh cadavers who gave written consent prior to death. The arms were stored at $-20^{\circ} \mathrm{C}$ without any further fixation and were only thawed to room temperature prior to starting the experiment.

Temperature sensing elements (TSE) containing platinumchip-sensors (Pt 1000, TYP PCA, 1.1505.10 M JUMO $\mathrm{GmbH} \&$ Co.KG, Fulda, Germany) were used for all experiments, measuring two temperatures per second, with an accuracy of $\pm 0.1^{\circ} \mathrm{C}$. Eight TSEs were used in total and placed adjacent to sensible structures in the wrist [20] in order to monitor temperature changes. TSE 1 was used as a reference to detect the temperature of the irrigation fluid at room temperature of $20^{\circ} \mathrm{C}$. Six TSEs were implanted by a proper skin incision followed by blunt dissection through the capsule using $2.5 \mathrm{x}$ magnifying lens under direct visualization, to the following locations on the wrist: TSE 2 was inserted intra-articular into the radial recess ( $\mathrm{rr}$ ). TSE 3 was placed into the scapho-lunate ligament (sl). TSE 4 was positioned into a hole of $2 \mathrm{~mm}$, which was drilled from the dorsal site and subchondral to the center of the lunate fossa (fl). TSE 5 was arranged intra-articularly at the distal radioulnar joint (druj) whereas TSE 6 was inserted into the extra-articular tendon sheath of the $4 / 5$ compartment $(4 / 5)$. TSE 7 was implanted adjacent to the ulnar nerve in alignment to the extra-articular ulno-carpal joint (un) (Figure 1). TSEs were fixed with a 4/0 Prolene suture and the capsule was closed.

Afterwards, the arms were fixed in the commercially available Acumed Arc Wrist Tower (Acumed, Hillsboro/ OR, USA), where finger traps and maximum distraction was applied (Figure 1). The final TSE 8 was located intra-articular and fixed during arthroscopy at the center of the midcarpal joint (mc).

A standard wrist arthroscopy was performed using the 3-4 portal for the overview and $6 \mathrm{R}$ portal for the $\mathrm{RF}$ probe. VAPR II $2.3 \mathrm{~mm}$ side effect electrodes (Depuy Mitek, Westwood, MA, USA) were used in order to operate bipolar currency. A Monopolar OPES ablator for small joints (45 REF AR-9601SJ-45 OPES Ablator AR-9600; Arthrex, Naples, FL, USA) was applied for all monopolar procedures.

All wrists were initially flushed with $\mathrm{NaCl} 0.9 \%$ until a temperature of $20^{\circ} \mathrm{C}$ was reached by all probes. Irrigation was applied at a pressure of $50 \mathrm{~mm} \mathrm{Hg}$ with an inflow rate of $50 \mathrm{~mL} / \mathrm{min}$. An 18-gauge needle in the $6 \mathrm{U}$ portal achieved the gravity-assisted outflow. Temperature was monitored and recorded by an 8-chanel custom build simultaneous measuring device.

The bipolar RF probe was used with a power of $60 \mathrm{~W}$ for ablation-mode and $45 \mathrm{~W}$ for coagulation-mode, whereas the monopolar RF probe settings were $20 \mathrm{~W}$ for cut-mode and $10 \mathrm{~W}$ for coagulation-mode.

The RF probe was continually moved backward and forward in a meandering pattern over the lunate fossa for a total of $45 \mathrm{~s}$ simulating a chondroplasty of the lunate fossa (Figure 1). In particular, RFE was first applied for 30s in the ablation-mode respectively the cut-mode followed without any break by $15 \mathrm{~s}$ coagulation-mode.

Afterwards, every wrist was dissected in order to validate correct placement of each TSE by measuring the distance to the location of the RF in millimeters. 


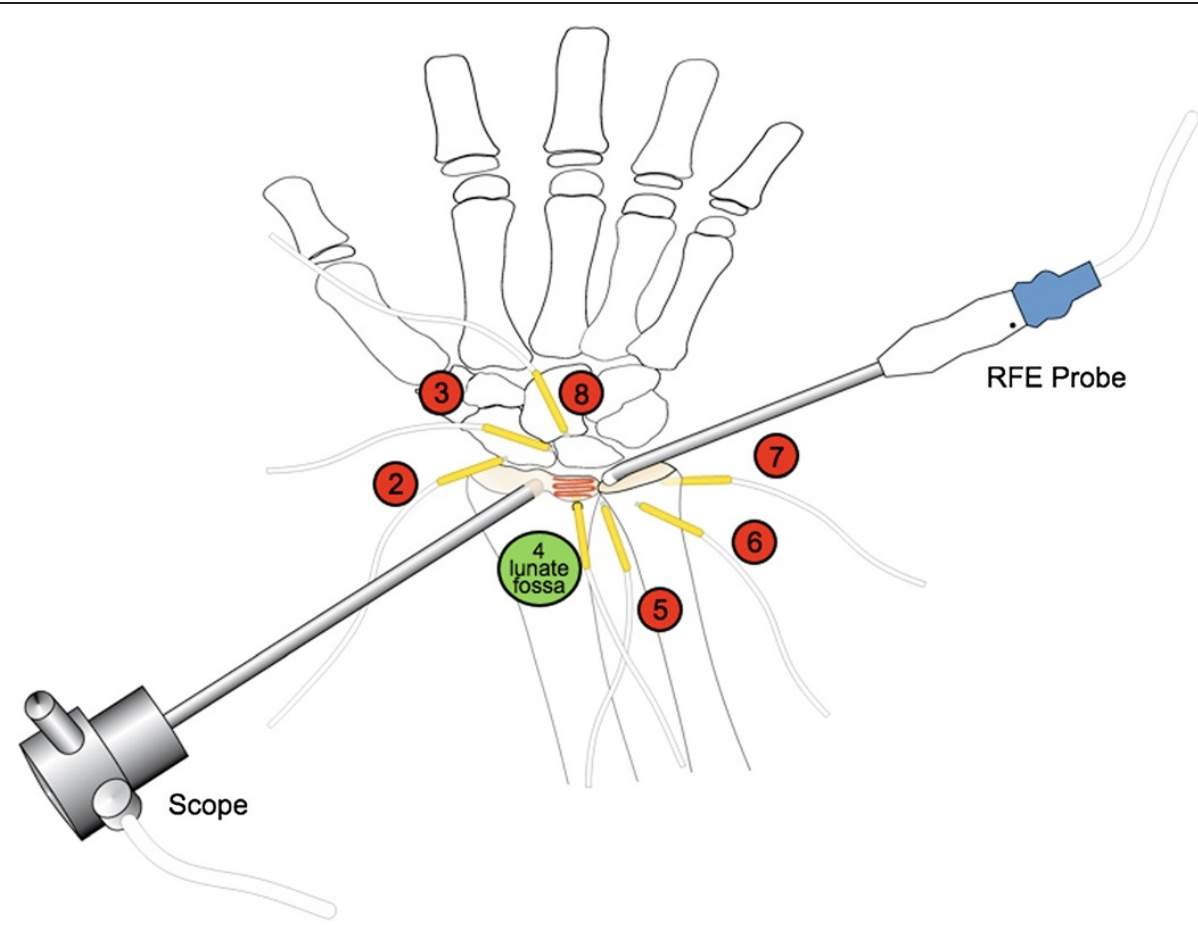

Figure 1 Temperature sensing elements (TSE) were placed adjacent to sensible structures in the wrist in order to monitor temperature changes. TSE 1 was used as a reference to detect the temperature of the irrigation fluid at room temperature of $20^{\circ} \mathrm{C}$. Seven TSEs were implanted under direct visualization to: radial recess ( $r r)$, scapho-lunate ligament (sl), dorsal site and subchondral to the center of the lunate fossa (fl), intra-articularly at the distal radioulnar joint (druj), extra-articular tendon sheath of the 4/5 compartment (4/5), ulnar nerve in alignment to the extra-articular ulno-carpal joint (un), intra-articular at the center of the midcarpal joint (mc).

Histograms and descriptive statistic were calculated to determine distributions and outliers. Values at $\mathrm{p}<0.05$ were considered as statistically significant. All statistical analysis was performed using the statistical software PASW Statistics 17 for Windows (SPSS Inc., Chicago, IL, USA). Since the underlying data were not normally distributed, non-parametric tests were applied (one-sided Spearman's rho coefficient, Kendall's tau coefficient and a two-tailed Mann-Whitney U test).

\section{Results}

The application of bipolar RFE over 45 seconds significantly increased the mean temperature at all TSEs ( $\leq \leq 0.002$; Spearman's rho coefficient $>0.4$ ). Interestingly, the mean temperature during the bRFE application did not exceeded $30^{\circ} \mathrm{C}$ except for the lunate fossa. with a peak of $40.16 \pm 11.42 \mathrm{C}^{\circ}$. Noteworthy, after bRFE for 45 seconds a plateau-like curve was detected at the lunate fossa followed by a decrement under $30^{\circ} \mathrm{C}$. In addition, the temperature increased even after switching to the coagulation-mode at the time point of 30 seconds (Figure 2A, Table 1).

As expected, the temperature decreased proportional to the distance of the RF-probe $(\mathrm{p}=0.005$; Kendall-Tau-b coefficient of correlation $=0.81$ ).

Similar results were obtained for the monopolar system with a significant increase of the mean temperature at all measurement points ( $\mathrm{p} \leq 0.001$; Spearman's rho coefficient $>0.84$ ). However, the maximum mean temperature only reached $33 \pm 8.9 \mathrm{C}^{\circ}$ after 34 seconds in the lunate fossa followed by a decrease to $28^{\circ} \mathrm{C}$. This is of interest, since switching the monopolar-device to the coagulation-mode after $30 \mathrm{~s}$ was associated with a decrease of the mean temperature, whereas the bipolar device was associated with a further temperature increase (Figure 2B, Table 2).

Similar to the bipolar system the temperature significantly decreased to the distance of the RF-probe $(\mathrm{p}=0.002$; Kendall-Tau-b coefficient of correlation $=0.905$ ).

Comparison of mean temperature revealed significant higher temperature values in the radial recess, the lunate fossa and the DRUJ when using the bipolar system $(\mathrm{p}<0.001)$. Interestingly, significantly higher temperatures were detected for the monoplar system at the sl-ligament, the 4/5 tendon sheath compartment, the ulnar nerve and the midcarpal joint ( $\mathrm{p} \leq 0.001)$. The mean temperature in the lunate fossa was significantly higher for the bipolar system when compared to the monopolar system $(\mathrm{p}<0.001)$ (Figure 3).

The maximum temperature was $69.21^{\circ} \mathrm{C}$ for the bipolar system detected in the lunate fossa whereas the peak temperature for the monoplar system in the lunate fossa was only $49.35^{\circ} \mathrm{C}$. Application with the bipolar system induced temperatures over $50^{\circ} \mathrm{C}$ in 3 wrists in each at 


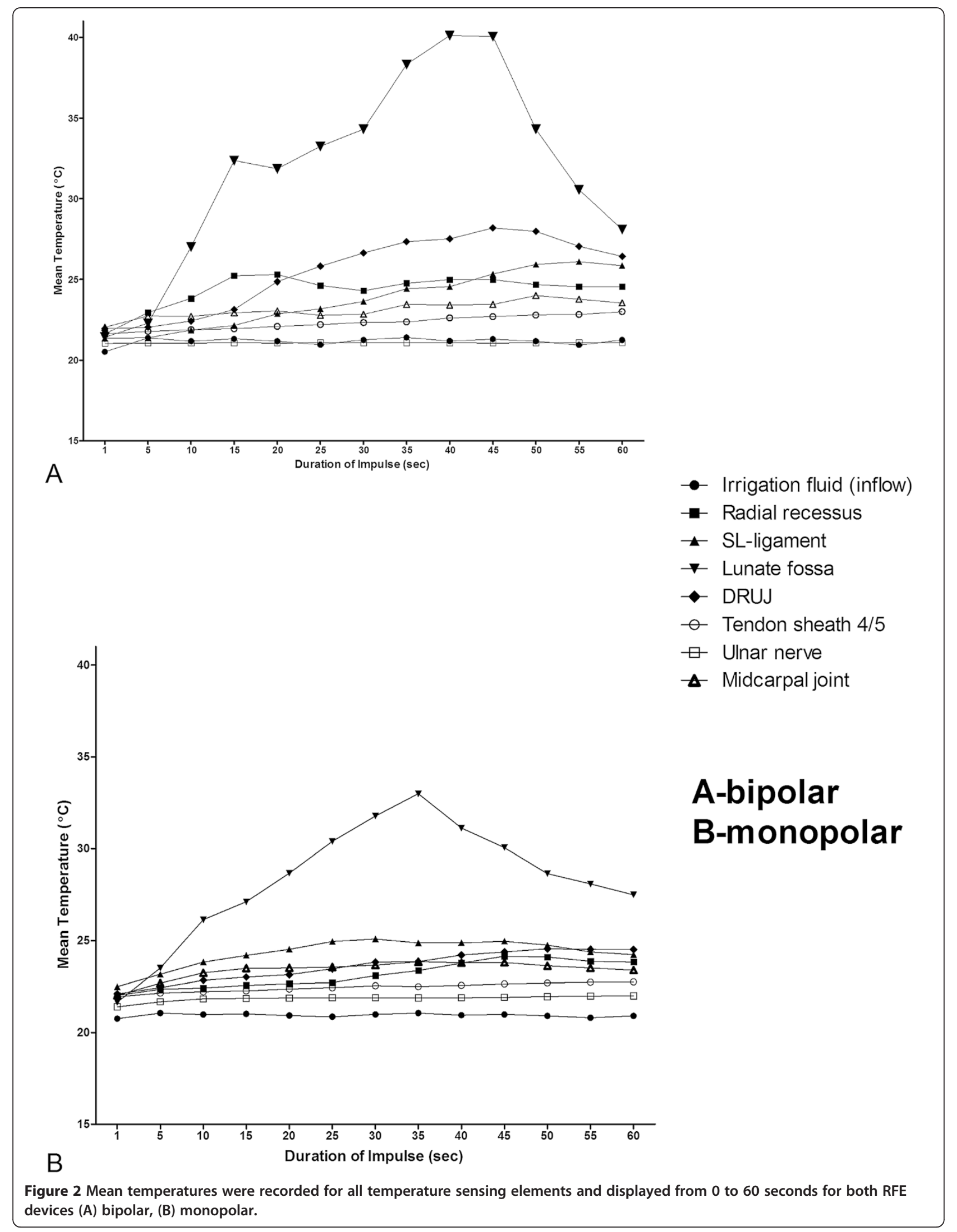


Table 1 Bipolar Device

\begin{tabular}{|c|c|c|c|c|c|c|c|c|}
\hline \multicolumn{9}{|c|}{ Mean Temperature + SD $\left({ }^{\circ} \mathrm{C}\right)$} \\
\hline & Irrigation fluid & Radial recessus & SL-ligament & Lunate fossa & DRUJ & Tendon sheath of $4 / 5$ Comp & Ulnar nerve & Midcarpal joint \\
\hline $0 \mathrm{~s}$ & $20,52 \pm 1,00$ & $21,61 \pm 1,48$ & $21,35 \pm 1,48$ & $21,42 \pm 0,93$ & $21,94 \pm 1,23$ & $21,62 \pm 0,68$ & $21,04 \pm 0,74$ & $22,03 \pm 1,05$ \\
\hline $5 \mathrm{~s}$ & $21,02 \pm 1,34$ & $23,10 \pm 1,89$ & $21,46 \pm 1,59$ & $22,93 \pm 1,04$ & $22,23 \pm 1,43$ & $21,81 \pm 0,65$ & $21,07 \pm 0,74$ & $22,76 \pm 1,50$ \\
\hline $10 \mathrm{~s}$ & $21,02 \pm 1,34$ & $24,81 \pm 5,25$ & $21,95 \pm 1,90$ & $30,03 \pm 12,63$ & $22,55 \pm 1,61$ & $21,91 \pm 0,69$ & $21,07 \pm 0,74$ & $22,74 \pm 1,37$ \\
\hline $15 \mathrm{~s}$ & $21,24 \pm 1,47$ & $25,03 \pm 3,36$ & $22,11 \pm 2,54$ & $33,54 \pm 14,30$ & $24,08 \pm 4,42$ & $21,98 \pm 0,75$ & $21,08 \pm 0,73$ & $22,88 \pm 1,52$ \\
\hline $20 \mathrm{~s}$ & $21,31 \pm 1,52$ & $24,61 \pm 2,75$ & $22,90 \pm 3,00$ & $31,60 \pm 7,16$ & $24,91 \pm 5,87$ & $22,11 \pm 0,83$ & $21,08 \pm 0,75$ & $22,89 \pm 1,48$ \\
\hline $30 \mathrm{~s}$ & $20,54 \pm 0,96$ & $24,35 \pm 2,32$ & $23,80 \pm 3,91$ & $33,42 \pm 8,49$ & $27,10 \pm 11,55$ & $22,37 \pm 1,22$ & $21,08 \pm 0,73$ & $22,88 \pm 1,15$ \\
\hline $40 \mathrm{~s}$ & $21,03 \pm 1,31$ & $24,93 \pm 2,97$ & $24,64 \pm 4,42$ & $40,16 \pm 11,42$ & $27,72 \pm 11,81$ & $22,63 \pm 2,13$ & $21,07 \pm 0,72$ & $23,43 \pm 1,93$ \\
\hline $45 \mathrm{~s}$ & $21,23 \pm 1,49$ & $24,93 \pm 3,15$ & $25,52 \pm 4,30$ & $38,24 \pm 9,36$ & $28,40 \pm 10,27$ & $22,71 \pm 2,26$ & $21,07 \pm 0,74$ & $23,50 \pm 2,20$ \\
\hline $60 \mathrm{~s}$ & $21,45 \pm 1,62$ & $24,54 \pm 2,00$ & $25,61 \pm 4,80$ & $27,82 \pm 3,55$ & $26,29 \pm 6,08$ & $23,09 \pm 3,00$ & $21,10 \pm 0,72$ & $23,51 \pm 1,70$ \\
\hline
\end{tabular}

different time points (15 s, $30 \mathrm{~s}, 45 \mathrm{~s})$ at the lunate fossa. In addition, when using the bipolar system a peak temperature of $54.15^{\circ} \mathrm{C}$ was detected in the DRUJ compared to $31.81^{\circ} \mathrm{C}$ for the monoploar System. The temperature of $50^{\circ} \mathrm{C}$ was never exceeded when using the monopolar system (Figure 4). The peak temperatures were significantly higher for the bipolar system $(p=0.043)$ when compared to the monopolar RFE.

\section{Discussion}

In this study we investigated the subchondral temperature profile during RFE application while mimicking a commonly performed chondroplasty in wrist arthroscopy. We found significantly higher subchondral mean temperatures and peak temperatures for the bipolar system when compared to the monopolar system. These results are in line with a previous study by Edwards et al. which measured cartilage matrix temperatures in different depth (200 $\mu \mathrm{m}, 500 \mu \mathrm{m}, 2000 \mu \mathrm{m})$ during the application of RFE. The authors demonstrated chondrocytes death even at a depth of $2000 \mu \mathrm{m}$ when using a bipolar system for 20s. In comparison application of mRFE induced an injury of chondrocytes only at a depth of $500 \mu \mathrm{m}$ [21]. Hence, Edwards et al have raised concerns over RFE for chondroplasty especially when chondral matrix is less than $3 \mathrm{~mm}$ [22]. We consider these results important as normal thickness of cartilage layer in the wrist is around 0.7 to $1.2 \mathrm{~mm}$ [19] and cartilage damage can occur at temperature of $45^{\circ} \mathrm{C}$ to $55^{\circ} \mathrm{C}[10,11]$.

$\mathrm{Lu}$ et al. reported that the mold and seal effect on delaminated cartilage can be obtained in a time dependent manner whereas $15 \mathrm{~s}$ application of RFE is required in order to get a detectable effect. Noteworthy, a signicantly higher smoothing grade was present after 30 s when compared to 20s applied. In the present study we decided to simulate a commonly used meander pattern for handling the RFE probe during the chondroplasty. In addition, a final coagulation mode was performed for $10 \mathrm{~s}$ after a 30s ablation-mode or cut mode in order to achieve a potential smooth surface [23].

We detected subchondral peak temperatures of almost $70^{\circ} \mathrm{C}$ when using the bipolar system and $50^{\circ} \mathrm{C}$ for the monopolar system. These results underline the potential risk for cartilage not only for the bipolar but also for the monopolar system since cartilage damage can occur at temperature around $45^{\circ} \mathrm{C}$. Interestingly, Lu et al. reported that bRFE caused significantly higher rate of chondrocyte death than mRFE in a bovine osteoarticular model.

Table 2 Monopolar Device

\begin{tabular}{|c|c|c|c|c|c|c|c|c|}
\hline \multicolumn{9}{|c|}{ Mean Temperature + SD $\left({ }^{\circ} \mathrm{C}\right)$} \\
\hline & Irrigation fluid & Radial recessus & SL-ligament & Lunate fossa & DRUJ & Tendon sheath of $4 / 5$ Comp & Ulnar nerve & Midcarpal joint \\
\hline $0 \mathrm{~s}$ & $20,75 \pm 1,45$ & $21,85 \pm 0,74$ & $22,19 \pm 1,02$ & $21,64 \pm 1,00$ & $22,10 \pm 0,56$ & $21,78 \pm 0,78$ & $21,39 \pm 1,28$ & $22,02 \pm 0,54$ \\
\hline $5 \mathrm{~s}$ & $20,91 \pm 1,53$ & $22,35 \pm 1,46$ & $23,16 \pm 1,51$ & $24,07 \pm 2,93$ & $22,48 \pm 1,07$ & $22,13 \pm 1,23$ & $21,67 \pm 1,74$ & $22,92 \pm 1,39$ \\
\hline $10 \mathrm{~s}$ & $20,91 \pm 1,53$ & $22,41 \pm 1,47$ & $23,83 \pm 1,66$ & $25,88 \pm 5,02$ & $22,86 \pm 1,44$ & $22,20 \pm 1,24$ & $21,84 \pm 2,03$ & $23,27 \pm 1,71$ \\
\hline $15 \mathrm{~s}$ & $20,96 \pm 1,59$ & $22,56 \pm 1,46$ & $24,19 \pm 2,05$ & $26,99 \pm 6,52$ & $23,06 \pm 1,52$ & $22,24 \pm 1,24$ & $21,82 \pm 2,04$ & $23,54 \pm 1,93$ \\
\hline $20 \mathrm{~s}$ & $20,99 \pm 1,65$ & $22,65 \pm 1,49$ & $24,52 \pm 2,58$ & $29,02 \pm 8,08$ & $23,21 \pm 1,58$ & $22,34 \pm 1,15$ & $21,85 \pm 2,03$ & $23,49 \pm 1,68$ \\
\hline $30 \mathrm{~s}$ & $20,69 \pm 1,34$ & $23,09 \pm 1,71$ & $25,08 \pm 3,19$ & $31,66 \pm 7,94$ & $23,87 \pm 2,26$ & $22,52 \pm 1,09$ & $21,89 \pm 2,02$ & $23,65 \pm 1,73$ \\
\hline $40 \mathrm{~s}$ & $20,87 \pm 1,42$ & $23,77 \pm 2,34$ & $24,88 \pm 3,11$ & $30,91 \pm 5,50$ & $24,30 \pm 3,09$ & $22,54 \pm 1,27$ & $21,90 \pm 2,04$ & $23,80 \pm 1,97$ \\
\hline $45 \mathrm{~s}$ & $20,94 \pm 1,46$ & $24,15 \pm 2,26$ & $24,96 \pm 2,96$ & $29,71 \pm 3,97$ & $24,38 \pm 3,13$ & $22,62 \pm 1,37$ & $21,92 \pm 2,04$ & $23,83 \pm 2,04$ \\
\hline $60 \mathrm{~s}$ & $20,98 \pm 1,50$ & $23,82 \pm 2,18$ & $24,23 \pm 2,33$ & $27,42 \pm 3,91$ & $24,52 \pm 3,20$ & $22,75 \pm 1,48$ & $21,99 \pm 2,08$ & $23,38 \pm 1,53$ \\
\hline
\end{tabular}




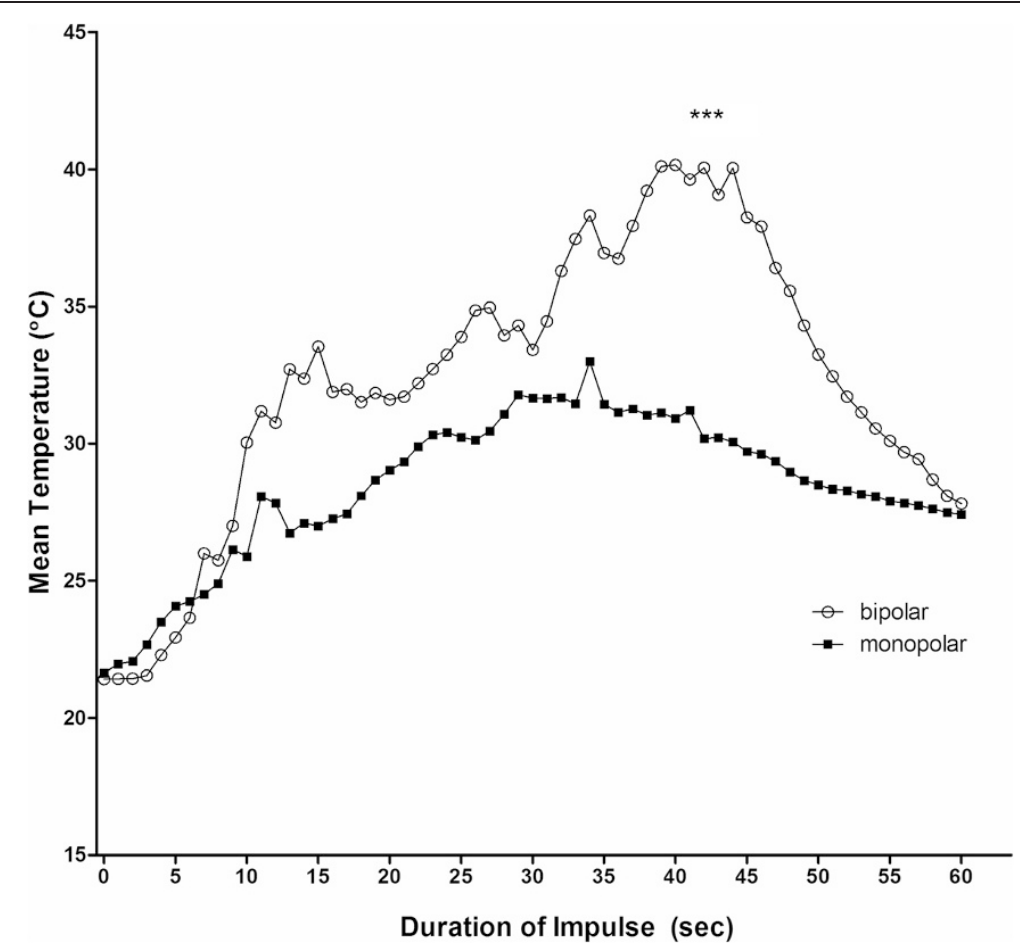

Figure 3 Mean temperatures were recorded from the sensing element at the subchondral lunate fossa during bipolar and monoplar RFE application. The mean temperature in the lunate fossa was significantly higher for the bipolar system when compared to the monopolar system $\left.{ }^{* * *} p<0.001\right)$.

Moreover, bRFE was more associated with a full-thickness chondrocyte death including the subchondral bone [15].

Recent studies suggest a sufficient irrigation system $[24,25]$ to reduce the temperature adjacent to the energy application. However, our data provide evidence that temperature levels remain critical for cartilage during chondroplasty especially when using the bipolar mode. Thus, it is highly questionable that the irrigation temperature has a cooling effect on the subchondral bone side.

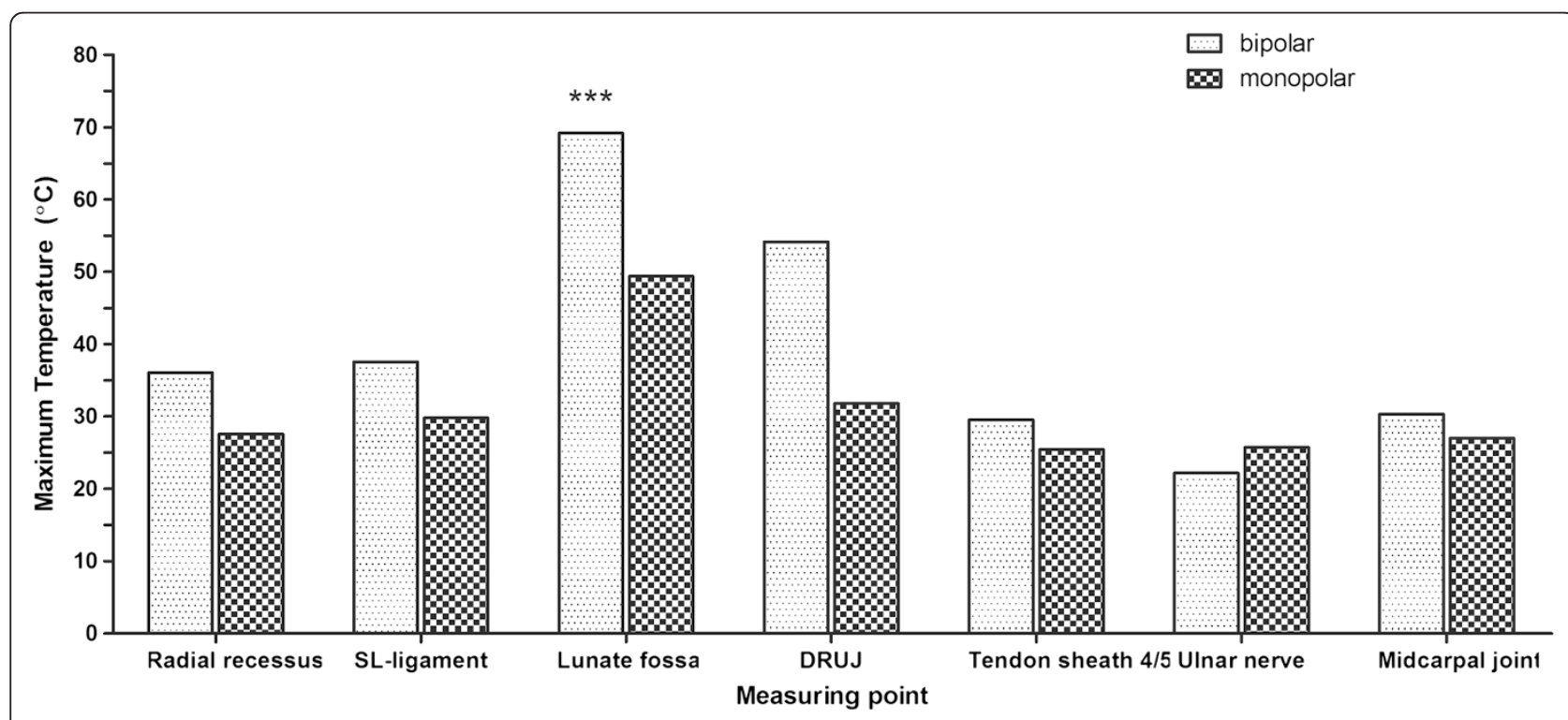

Figure 4 The maximum temperature of $69.21^{\circ} \mathrm{C}$ was detected in the lunate fossa for the bipolar system whereas the peak temperature was only $49.35^{\circ} \mathrm{C}$ for the monoplar system at the same location. In addition, peak temperature in the DRUJ reached $54.15^{\circ} \mathrm{C}$ when using the bipolar system but only $31.81^{\circ} \mathrm{C}$ for the monoploar application. The temperature of $50^{\circ} \mathrm{C}$ was never exceeded when using the monopolar system. 
Notably, our results indicate a different distribution of the heat when comparing bRFE and mRFE due to their different mode of operation [22,26]. Therefore, irrigation might have a cooling effect for the monopolar system since the currency runs towards the grounding electrode. We found that the temperature profile decreased for the monopolar device when switching to the lower energy setting whereas temperature values still increased for the bipolar system especially in the radial recess, the lunate fossa and the DRUJ. Peak temperature for the bRFE received $50^{\circ} \mathrm{C}$ after $15 \mathrm{~s}$ in $14.3 \%$ and after $24 \mathrm{~s}$ in $28.6 \%$ of the cases in both the lunate fossa and the DRUJ. However, this was not apparent for the monopolar device since the mean temperature did not exceed $30^{\circ} \mathrm{C}$ at these two specific locations. Our data indicate that even chondrocytes in the DRUJ might be under risk when using bRFE. In contrast, the mean temperature for the monopolar system was significantly higher in the sl ligament, the midcarpal joint, the $4 / 5$ tendon sheath and the ulnar nerve.

But this might be caused by the location of the indifferent electrode which had to be placed at the posterior side of the forearm due to the experimental setting. It is well known that electrosurgical current during monopolar applications can cause tissue damage at patient's skin. Especially, skin areas are affected which have contact to wet underground or cover while no appropriate indifferent electrode was attached to the patient. Fickeling et al. demonstrated that increasing current causes an increase of the temperature at the indifferent electrode since the dispersion of the current is limited by the size of the attached electrode [27]. Thus, the reported higher temperature in the sl ligament, the midcarpal joint, the $4 / 5$ tendon sheath and the ulnar nerve during monopolar application might be disproportional high caused by small distance between monopolar probe and indifferent electrode.

Kosey et al. recommended a constant movement of the probe during RFE application in order to limit the risk of chondrocyte damage by minimizing the point heating [16]. However, our results indicate that even under probe movement a harmful temperature level can be reached at the side of treatment.

Noteworthy, chondroplasty exhibit a potential risk of osteonecrosis since Li et al. reported apoptosis and necrosis for osteoblasts in a temperature-range of $48-52^{\circ} \mathrm{C}$ [28]. In line, several cases of osteonecrosis have already been described after RFE in knee arthroscopy [29,30].

Our data support previous findings regarding peak temperatures in the subchondral bone for the bipolar system $\left(70^{\circ} \mathrm{C}\right)$ and for the monopolar system $\left(50^{\circ} \mathrm{C}\right)$ which underlines the potential risk for the subchondral bone. However, effects of RFE at the subchondral bone have been reported to be reversible [31]. The underlying repair mechanism might explain that no evidence of avascular necrosis (AVN) in MRI imaging was apparent
12 month after mRFE application along with shaver usage in knee arthroscopy [3].

Despite the potential risk of temperature injuries there is clinical evidence from prospective, randomized controlled trials, which shows an improved functional outcome and decreased pain after RFE application [16]. However, to date it remains unclear whether the pain reduction is caused by delayed cartilage degradation or coagulation of intraarticular sensory receptors. Thus, the application of RFE for chondroplasty still requires more research in order to estimate potential risk and real advantage [32]. Kosey reported a discrepancy between the estimated side effects of RFE and clinical outcomes. Moreover, he recommended further research focusing on the long-term effect of RFE and the probe design [16].

\section{Limitation}

The experimental setup cannot be compared to an arthroscopy performed on patients due to the higher body temperature in living humans compared to the baseline cadaver temperature of $20^{\circ} \mathrm{C}$. We assume hat the peak temperature might be up to $10^{\circ} \mathrm{C}$ to $13^{\circ} \mathrm{C}$ higher than measured results in our experiment since the body temperature in the extremities on living human is around $33^{\circ} \mathrm{C}$ to $35^{\circ} \mathrm{C}$. We did not perform power analysis prior conducting this study because of similar data of recently published cadaver studies. In addition, the temperature of the employed irrigation fluid can alter the results.

\section{Conclusion}

It remains debatable whether RFE is a safe application for chondroplasty in wrist arthroscopy under continuous irrigation and constant movement. However, the bipolar device should be applied with more caution since peak temperature in the lunate fossa almost reached $70^{\circ} \mathrm{C}$ even under continuous irrigation.

\section{Abbreviations}

RFE: Radiofrequency energy; RF: Radiofrequency; bRFE: Bipolar radiofrequency energy; mRFE: Monopolar radiofrequency energy; MS: Mechanical shaving; MD: Mechanical debridement; ${ }^{\circ} \mathrm{C}$ : Degree Celsius; TSE: Temperature sensing elements; rr: Radial recess; sl: Scapholunate ligament; fl: Lunate fossa; druj: Distal radioulnar joint; 4/5: Tendon sheath of the 4/5 compartment; un: Ulnar nerve; mc: Midcarpal joint; W: Watt; S: Seconds.

\section{Competing interests}

The authors declare that they have no competing interest.

\section{Authors' contributions}

$\mathrm{MH}$ conceived of the study, participated in its conception and design, supervised the study, is the main author; CE performed the statistical analysis and helped draft the manuscript; JZ performed the acquisition of data and helped draft the manusscript; ML performed the acquisition of data and helped draft the manusscript; $A B$ performed the acquisition of data and helped draft the manusscript; RK developed the 8-chanel custom build simultaneous measuring device; made substantial contributions to the conception an the design of the study. MN made substantial contribution to the design, was a contributor revising the manuscript; SG was a major contributor in analyzing and interpretation of the data and in writing the manuscript. All authors have read and approved the final manuscript. 


\section{Acknowledgment}

The authors thank Dieter Pirner for his valuable graphic support.

\section{Author details}

${ }^{1}$ Department of Trauma Surgery, University Medical Center Regensburg, Franz-Josef-Strauss-Allee 11, 93053 Regensburg, Germany. ${ }^{2}$ Center for Medical Biotechnology, University of Regensburg, Regensburg, Germany. ${ }^{3}$ Department of Orthopedic Surgery, University Hospital Basel, Basel, Switzerland.

Received: 27 August 2014 Accepted: 12 January 2015

Published online: 31 January 2015

\section{References}

1. Brittberg M, Winalski CS. Evaluation of cartilage injuries and repair. J Bone Joint Surg Am. 2003;85-A Suppl 2:58-69.

2. Spahn G, Kahl E, Mückley T, Hofmann GO, Klinger HM. Arthroscopic knee chondroplasty using a bipolar radiofrequency-based device compared to mechanical shaver: results of a prospective, randomized, controlled study. Knee Surg Sports Traumatol Arthrosc. 2008;16:565-73.

3. Barber FA, Iwasko NG. Treatment of grade III femoral chondral lesions: mechanical chondroplasty versus monopolar radiofrequency probe. Arthroscopy. 2006;22:1312-7.

4. Khan AM, Dillingham MF. Electrothermal chondroplasty-monopolar. Clin Sports Med. 2002;21:663-74.

5. Lu Y, Edward RB, Nho S, Cole BJ, Markel MD. Lavage solution temperature influences depth of chondrocyte death and surface contouring during thermal chondroplasty with temperature-controlled monopolar radiofrequency energy. Am J Sports Med. 2002;30:667-73.

6. Voss JR, Lu Y, Edwards RB, Bogdanske JJ, Markel MD. Effects of thermal energy on chondrocyte viability. Am J Vet Res. 2006;67:1708-12.

7. Yasura K, Nakagawa Y, Kobayashi M, Kuroki H, Nakamura T. Mechanical and biochemical effect of monopolar radiofrequency energy on human articular cartilage: an in vitro study. Am J Sports Med. 2006;34:1322-7.

8. Turner AS, Tippett JW, Powers BE, Dewell RD, Mallinckrodt CH. Radiofrequency (electrosurgical) ablation of articular cartilage: a study in sheep. Arthroscopy. 1998;14:585-91.

9. Edwards RB, Lu Y, Cole BJ, Muir P, Markel MD. Comparison of radiofrequency treatment and mechanical debridement of fibrillated cartilage in an equine model. Vet Comp Orthop Traumatol. 2008;21:41-8.

10. Benton HP, Cheng TC, MacDonald MH. Use of adverse conditions to stimulate a cellular stress response by equine articular chondrocytes. Am J Vet Res. 1996;57:860-5

11. Kaplan LD, Ernsthausen JM, Bradley JP, Fu FH, Farkas DL. The thermal field of radiofrequency probes at chondroplasty settings. Arthroscop. 2003;19:632-40.

12. Owens BD, Stickles BJ, Balikian P, Busconi BD. Prospective analysis of radiofrequency versus mechanical debridement of isolated patellar chondral lesions. Arthroscopy. 2002;18:151-5.

13. Uthamanthil RK, Edwards RB, Lu Y, Manley PA, Athanasiou KA, Markel MD. In vivo study on the short-term effect of radiofrequency energy on chondromalacic patellar cartilage and its correlation with calcified cartilage pathology in an equine model. J Orthop Res. 2006;24:716-24.

14. Dutcheshen N, Maerz T, Rabban P, Haut RC, Button KD, Baker KC, et al. The acute effect of bipolar radiofrequency energy thermal chondroplasty on intrinsic biomechanical properties and thickness of chondromalacic human articular cartilage. J Biomech Eng. 2012;134:081007.

15. Lu Y, Edwards RB, Cole BJ, Markel MD. Thermal chondroplasty with radiofrequency energy. An in vitro comparison of bipolar and monopolar radiofrequency devices. Am J Sports Med. 2001;29:42-9.

16. Kosy JD, Schranz PJ, Toms AD, Eyres KS, Mandalia VI. The use of radiofrequency energy for arthroscopic chondroplasty in the knee. Arthroscopy. 2011;27:695-703.

17. DeWal H, Ahn A, Raskin KB. Thermal energy in arthroscopic surgery of the wrist. Clin Sports Med. 2002;21:727-35.

18. Slutsky DJ, Nagle DJ. Wrist arthroscopy: current concepts. J Hand Surg [Am]. 2008:33:1228-44.

19. Schmidt H, Lanz U. Surgical Anatomy of the Hand. 1st ed. Thieme; 2004. p. 267.

20. Pell RF, Uhl RL. Complications of thermal ablation in wrist arthroscopy. Arthroscopy. 2004;20 Suppl 2:84-6.
21. Edwards RB, Lu Y, Rodriguez E, Markel MD. Thermometric determination of cartilage matrix temperatures during thermal chondroplasty: comparison of bipolar and monopolar radiofrequency devices. Arthroscopy. 2002;18:339-46.

22. Edwards RB, Lu Y, Markel MD. The basic science of thermally assisted chondroplasty. Clin Sports Med. 2002;21:619-47.

23. Lu Y, Edwards RB, Nho S, Heiner JP, Cole BJ, Markel MD. Thermal chondroplasty with bipolar and monopolar radiofrequency energy: effect of treatment time on chondrocyte death and surface contouring. Arthroscopy. 2002;18:779-88.

24. Huber M, Eder C, Mueller M, Kujat R, Roll C, Nerlich M, et al. Temperature Profile of Radiofrequency Probe Application in Wrist Arthroscopy: Monopolar Versus Bipolar. Arthroscopy. 2013;29:645-52.

25. Sotereanos DG, Darlis NA, Kokkalis Z, Zanaros G, Altman G, Miller M. Effects of radiofrequency probe application on irrigation fluid temperature in the wrist joint. J Hand Surg [Am]. 2009;34:1832-7.

26. Wienecke $H$, Lobenhoffer $P$. Basic principles of radiosurgical systems and their applications in arthroscopy. Unfallchirurg. 2003;106:2-12.

27. Fickling J, Loeffler CR. Does placement of the patient return electrode make a difference? Hotline News. 1997;2:1-2.

28. Li S, Chien S, Brånemark PI. Heat shock-induced necrosis and apoptosis in osteoblasts. J Orthop Res. 1999;17:891-9.

29. Bonutti PM, Seyler TM, Delanois RE, McMahon M, McCarthy JC, Mont MA Osteonecrosis of the knee after laser or radiofrequency-assisted arthroscopy: treatment with minimally invasive knee arthroplasty. J Bone Joint Surg Am. 2006;88 Suppl 3:69-75

30. Encalada I, Richmond JC. Osteonecrosis after arthroscopic meniscectomy using radiofrequency. Arthroscopy. 2004;20:632-6.

31. Balcarek $P$, Kuhn A, Weigel A, Walde TA, Ferlemann KG, Stürmer KM, et al. Impact of monopolar radiofrequency energy on subchondral bone viability. Knee Surg Sports Traumatol Arthrosc. 2010;18:673-80.

32. Arnoczky SP, Aksan A. Thermal modification of connective tissues: basic science considerations and clinical implications. J Am Acad Orthop Surg. 2000;8:305-13.

\section{Submit your next manuscript to BioMed Central and take full advantage of:}

- Convenient online submission

- Thorough peer review

- No space constraints or color figure charges

- Immediate publication on acceptance

- Inclusion in PubMed, CAS, Scopus and Google Scholar

- Research which is freely available for redistribution

Submit your manuscript at www.biomedcentral.com/submit
C BioMed Central 